\title{
Cytogenetic analysis of Liza ramada (Pisces, Perciformes) by different staining techniques and fluorescent in situ hybridization
}

\author{
ANNA RITA ROSSI* $\dagger \ddagger$ EKATERINA GORNUNG $+\&$ DONATELLA CROSETTI $\ddagger$ \\ †Department of Animal and Human Biology, University of Rome 1, Via A. Borelli 50, 00161 Rome and $\ddagger / C R A M$, \\ Central Institute for Marine Research, Via L. Respighi 5, 00197 Rome, Italy
}

\begin{abstract}
A cytogenetic investigation was carried out on specimens of Liza ramada, a mugilid species common in the Mediterranean sea. The analysis of chromosomes was performed through Ag-staining, C-banding, chromomycin $\mathrm{A}_{3}$ and DAPI staining, and fluorescent in situ hybridization with ribosomal genes. The results obtained are discussed with respect to cytotaxonomic implications and to the features of NORs.
\end{abstract}

Keywords: cytotaxonomy, FISH, heterochromatin, karyotype, mullet, NOR.

\section{Introduction}

Liza ramada is a mugilid species (grey mullet) that inhabits the Mediterranean Sea, the Black Sea and the Atlantic Ocean from Morocco to Scandinavia (Tortonese, 1975). In the Mediterranean this fish is quite common and lives sympatrically with other mullets that show similar external morphology, including three congeneric species, $L$. saliens, $L$. aurata and $L$. carinata. Previous cytogenetic studies on five, out of more than 20 Liza species (Table 1), reported the chromosome number and morphology, and the location of silver stained nucleolar organizer regions (Ag-NORs), but further data on NORs and on heterochromatin distribution and composition are still lacking. This paper reports karyological data on $L$. ramada obtained through several staining techniques, including fluorochrome staining and fluorescent in situ hybridization (FISH), and analyses these data from a cytotaxonomic perspective.

\section{Materials and methods}

Eleven specimens of $L$ ramada were collected from Civitavecchia (Italy), transported to the laboratory of the Department of Human and Animal Biology and kept alive until processed. Metaphases were obtained from cephalic kidney and spleen after injection of $0.1 \mathrm{~mL}$ of $1 \mathrm{mg} / \mathrm{mL}$ Colcemid, following the standard air-drying procedure. Colloidal silver

*Correspondence. E-mail: sola@axrma.uniromal.it staining of NORs was performed following Howell \& Black (1980), and C-banding according to Sumner (1972). Fluorochrome staining with chromomycin $A_{3}$ $\left(\mathrm{CMA}_{3}, \mathrm{GC}\right.$-specific) and DAPI (AT-specific) was carried out as described in Sola et al. (1992). In situ hybridization was carried out with a $2 \mathrm{~kb}$ fragment of human 18S rDNA biotinilated probe following Lawrence et al. (1988).

\section{Results}

Cytogenetic observations are reported in Table 2. Among the 48 chromosomes of the complement, only the two smallest ones, pair 24 , are identifiable both for their size and for the presence of short arms (Fig. 1a). Sequential staining with Giemsa and silver nitrate (Fig. 1a,b, respectively) revealed the presence of active nucleolar organizer regions located terminally on the short arms of these chromosomes. No other NOR was detected with silver staining. The number of Ag-NORs was verified by counting the number of Ag-nucleoli in the nucleus (Table 2). Differences in size of the two NORs were found, some of the specimens exhibiting homomorphic (Fig. 1c), others heteromorphic NORs (Fig. 1d).

Hybridization with the rDNA probe confirmed the number and location of Ag-NORs as well as NOR heteromorphism. In some specimens, differences in intensity and size of the hybridization signal were detected between homologues such that one of the NORs appeared twice as long as its homologue 
Table 1 Cytogenetic studies on Liza species

\begin{tabular}{|c|c|c|c|c|c|}
\hline Species & $2 n$ & Karyotype & $\mathrm{FN}^{*}$ & $\mathrm{NOR} \dagger$ & Reference \\
\hline L. aurata (Risso, 1810) & 48 & $48=46 a+2 s t$ & $(48)$ & \multirow{4}{*}{ A } & Cataudella et al., 1974 \\
\hline L. aurata (Risso, 1810) & 48 & $48=46 a+2 \mathrm{sm}$ & $(48)$ & & Delgado et al., 1991 \\
\hline L. aurata (Risso, 1810) & 48 & $48=46 a+2 s m$ & 50 & & Delgado et al., 1992 \\
\hline L. macrolepis (Smith, 1849) & 48 & $48=48 a$ & $(48)$ & & Choudhury et al., 1979 \\
\hline L. ramada (Risso, 1826) & 48 & $48=46 a+2 s t$ & $(48)$ & \multirow{5}{*}{ A } & Cataudella \& Capanna, 1973 \\
\hline L. ramada (Risso, 1826) & 48 & $48=46 a+2 s t$ & $(48)$ & & Cataudella et al., 1974 \\
\hline L. ramada (Risso, 1826) & 48 & $48=46 a+2 s m$ & $(48)$ & & Delgado et al., 1991 \\
\hline L. ramada (Risso, 1826) & 48 & $48=46 a+2 s m$ & 50 & & Delgado et al., 1992 \\
\hline L. saliens (Risso, 1810) & 48 & $48=46 a+2 s t$ & $(48)$ & & Cataudella et al., 1974 \\
\hline
\end{tabular}

*When in parentheses, fundamental number calculated by present authors.

$\uparrow \mathrm{A}, \mathrm{Ag}-\mathrm{NOR}$ localization on the short arms of the submetacentric chromosome pair.

Table 2 Summary of cytogenetic observations on Liza ramada

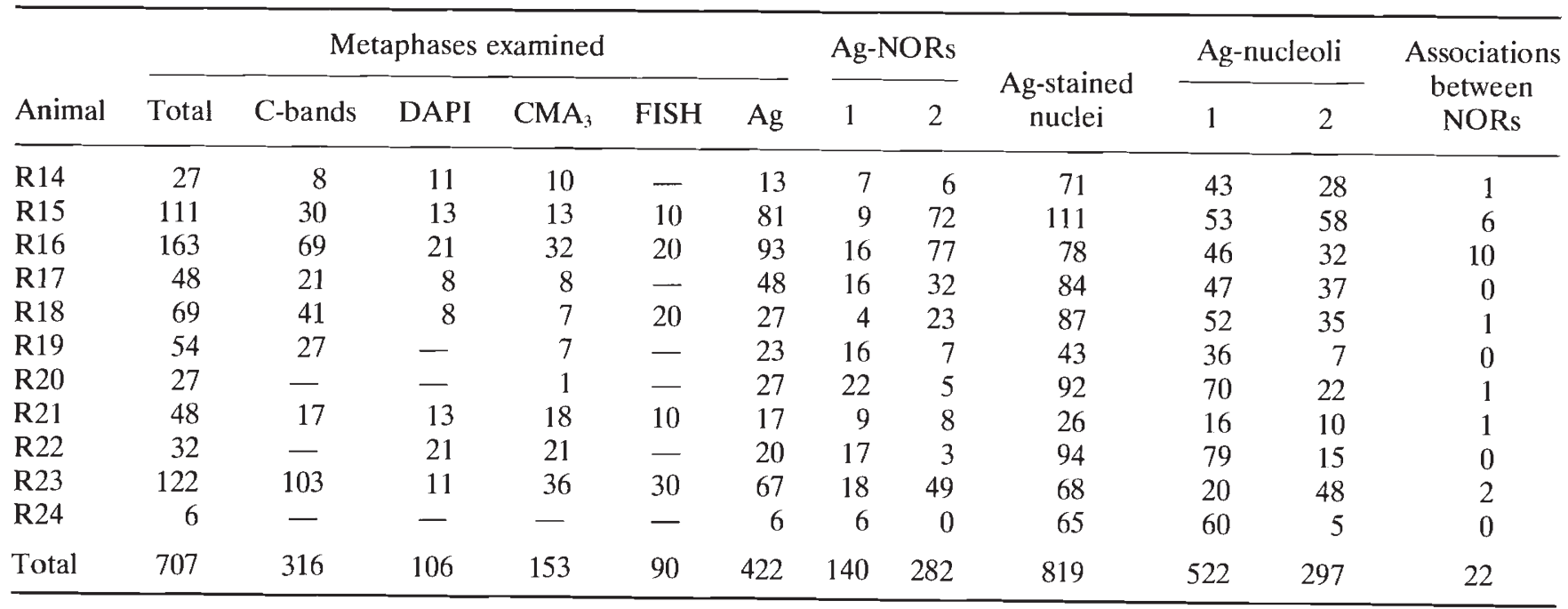

(Fig. 2a). Hybridization signals were scattered throughout the whole short arm of chromosome pair 24 (Fig. 2a,c), as evident from observing the same chromosomes DAPI-counterstained (Fig. 2b,d). A similar pattern was obtained with chromomycin $\mathrm{A}_{3}$ (Fig. 3a) both on untreated slides and after FISH. The GC-rich chromosome regions revealed by this fluorochrome include the centromeres of all the chromosomes, and the sites of the Ag-NORs and their flanking regions, as proved by the bright staining of the entire short arms of chromosome pair 24 (Fig. 3a and 2e).

DAPI staining produced a pale fluorescence on the GC-rich NORs, and a uniform staining along the rest of the chromosome arms including the centromeres. Thus, no AT-rich chromosome region was found.

C-banding showed a mostly pericentromeric location of heterochromatin in L. ramada. Heterochromatic blocks were present at the centromeres of all chromosomes and on the whole short arms of chromosomes pair 24, including NORs (Fig. 3b).

\section{Discussion}

A karyotype composed of 48 acrocentric chromosomes is considered to be ancestral for all teleosts (Ohno, 1974), and it is shown by 211 among 660 


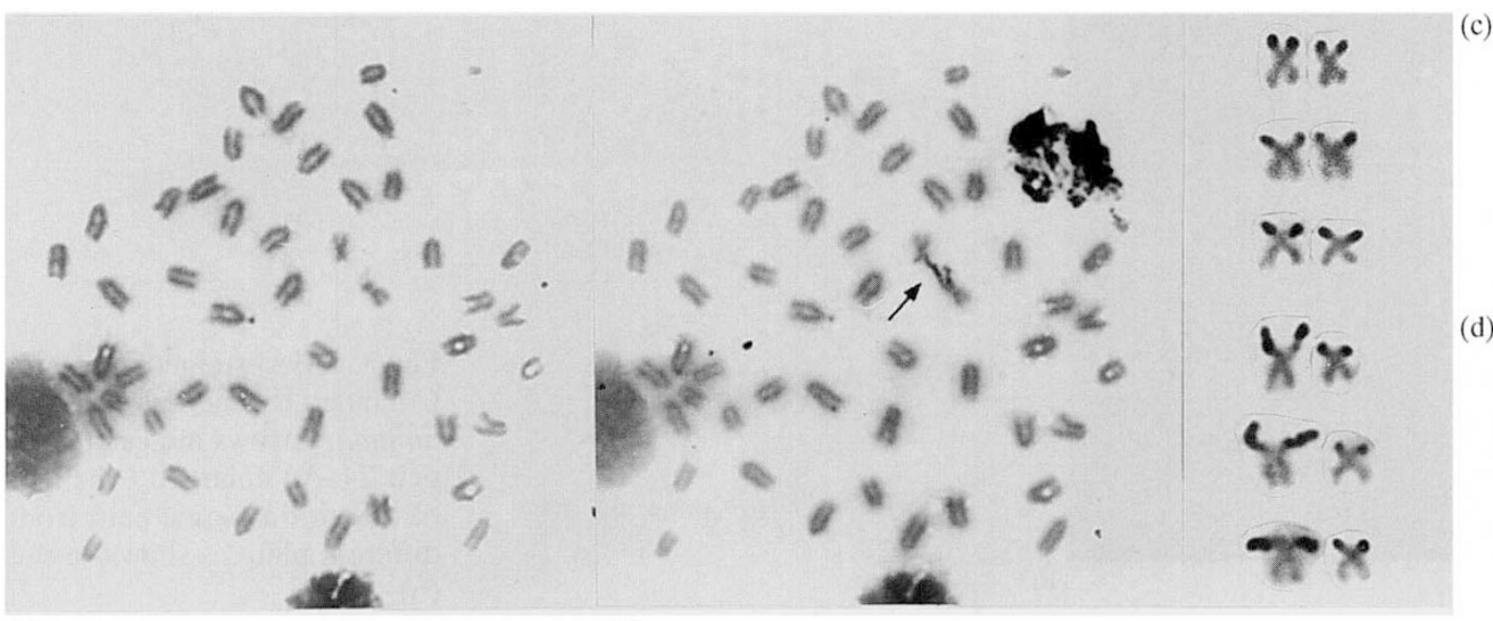

(a)

(b)

Fig. 1 Giemsa stained (a) and subsequently silver stained (b) metaphase plate of L. ramada. Arrows indicate Ag-NORs. Selected samples (c,d) of chromosome pair 24 after silver staining, showing homomorphic (c) or heteromorphic (d) NORs.

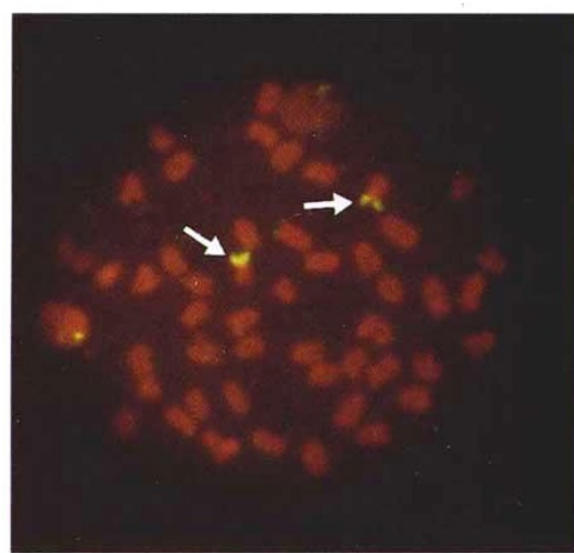

2.
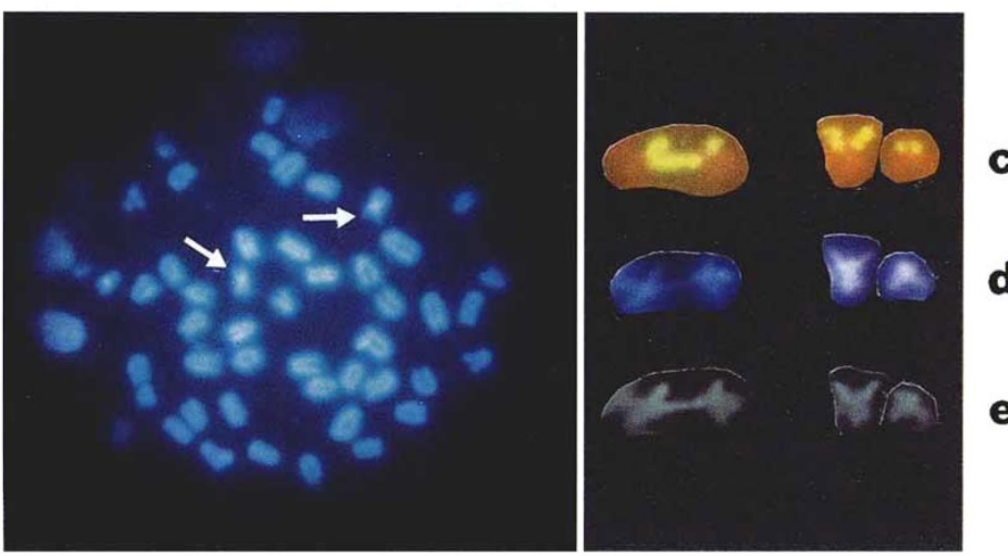

b

Fig. 2 rDNA FISH (a) and DAPI counterstaining (b) of the same metaphase of Liza ramada. Arrows indicate chromosome pair 24. In (c-e) enlarged samples of this chromosome pair after FISH (c), DAPI (d) and sequential CMA staining $_{3}$ (e). Note the bright positive signals on the whole short arms in (c) and (e), and the light negative signals of the same chromosome regions in (d).

species of Perciformes so far karyotyped (Klinkhardt et al., 1995). For the five mugilid species investigated for this a maximum of two NORs has been found, located on the telomeric region of the long arms of chromosome pair 1 in Mugil platanus (Jordão et al., 1992) and M. cephalus (Rossi et al., 1996), and on the short arms of chromosome pair 24 in Liza species (Table 2) and in Chelon labrosus (Delgado et al., 1991). It is therefore possible to hypothesize that the Liza and the Chelon karyotypes were derived from a translocation event that affected the acrocentric ancestral chromosome complement found in Mugil that involved NORs. This hypothesis seems to be supported by comparing several features of the karyotypes. In the two mentioned Mugil species, the larger size of chromosome pair I makes these chromosomes much more easily identifiable among the remaining ones of the karyotype than in Liza and Chelon. Meanwhile the presence of bibrachial chromosome (pair 24) characterizes only the species of the last two genera, similar chromosomes being absent in Mugil (Fig. 4). The mostly pericentromeric distribution of constitutive heterochromatin is similar to that already reported for the only two other mugilid species for which comparative data are available, $M$. platanus (Jordão et al., 1992) and

(C) The Genetical Society of Great Britain, Heredity, 79, 83-87. 


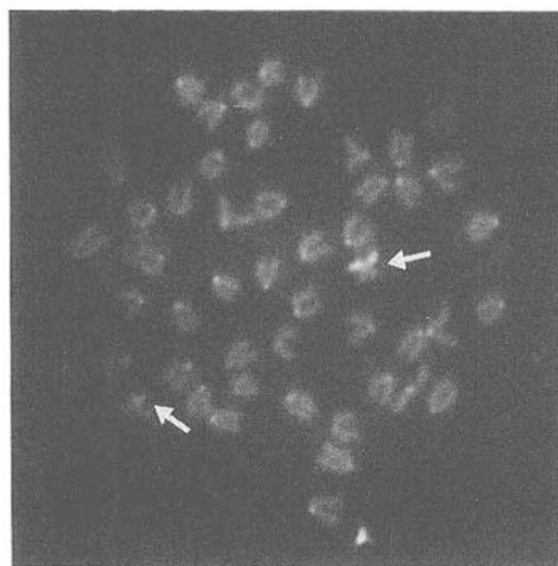

(a)

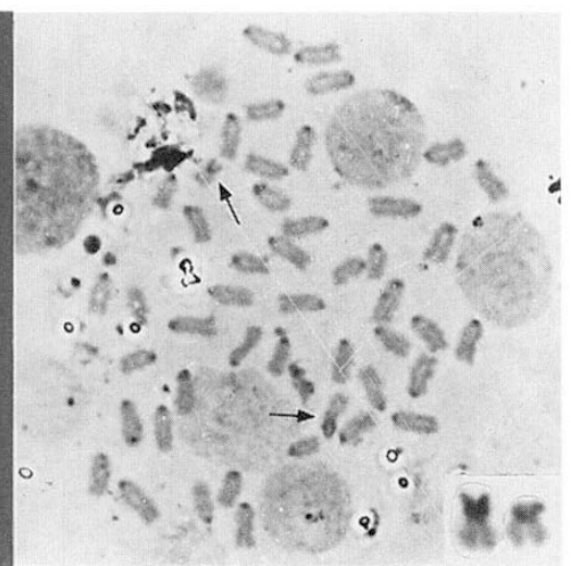

(b)
Fig. $3 \mathrm{CMA}_{3}$-stained (a), and C-banded (b) metaphases of Liza ramada. Arrows indicate chromosome pair 24. An enlarged C-banded sample of this chromosome pair, from a different plate, is shown in the inset in (b).

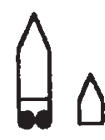

(a)

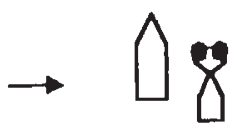

(b)
Fig. 4 Schematic representation of chromosome pairs 1 and 24 in Mugil cephalus and M. platanus (a), and in Liza and Chelon labrosus (b). Black dots on the chromosomes represent Ag-NORs. Differences in the shape and size of the chromosomes could be explained by a translocation event affecting the all-acrocentric karyotype.

M. cephalus (Rossi et al., 1996). In the former species no other C-positive site was detected, whereas in both $M$. cephalus and L. ramada a further heterochromatic block was associated with the NORs. GC/AT-specific staining showed that in spite of this similar distribution, the base composition of the pericentromeric heterochromatin was different in the two species. A uniform base composition was observed in $M$. cephalus, whereas in $L$. ramada this heterochromatin was brightly stained with $\mathrm{CMA}_{3}$, i.e. GC-rich, compared to what is commonly reported for fish, where only NORs are generally known as preferential sites of GC-accumulation.

As far as NORs are concerned, the results obtained after silver nitrate, $\mathrm{CMA}_{3}$ staining and FISH showed a perfect correspondence in the number of active and constitutive NORs, but only a partial correspondence in the extent of the chromosomal regions involved. The presence of silver nitrate signals, indicating active NORs, is restricted to the terminal part of the chromosome arm, but the positiveness of the whole chromosome arm after
$\mathrm{CMA}_{3}$ and FISH prove the presence of a wider rDNA site. A similar case has already been reported in Atlantic salmon, where it was interpreted as a consequence of NORs-interspersed heterochromatin (Pendas et al., 1993a); 16 minor transcriptionally inactive NORs were also identified after rDNA/ FISH in brown trout (Pendas et al., 1993b). We think that in $L$. ramada part of the NOR could be either silent, because of a different condensation of the rDNA-containing chromatin, or transcriptionally active but at a nondetectable rate. Whichever is the case, the presence of NORs flanking GC-rich heterochromatin, quite common in fish (Amemiya \& Gold, 1986; Mayr et al., 1988; Phillips \& Hartley, 1988), associated and/or interspersed to rDNA, could explain heteromorphism of NORs (Pendas et al., 1993a,b; Salvadori et al., 1995) as a polymorphism in the number of ribosomal sequences, although the origin of such heterochromatin remains unclear. In Atlantic eels (Salvadori et al., 1995) and lake trout (Reed \& Phillips, 1995) FISH demonstrated that telomeric sequences constitute NOR-associated GC-rich heterochromatin, and hybridize to NORs. Further experiments of in situ hybridization with (TTAGGG) $)_{n}$ probes would probably clarify whether this is true in $L$. ramada, and therefore if rDNA-associated heterochomatin contains telomeric sequences in this species.

\section{Acknowledgements}

The authors are grateful to L. Sola for her helpful comments and valuable suggestions on the manuscript, and to L. Veroli for technical assistance. This work was supported by the Ministry of Agriculture, General Directorate for Fisheries and Aquaculture, 
within the third 3-year National Plan for Fisheries and Aquaculture.

\section{References}

AMEMiyA, c. T. AND Gold, J. R. 1986. Chromomycin $A_{3}$ stains nucleolus organizer regions of fish chromosomes. Copeia, 1986, 226-231.

AREFYEV, V. A. 1989. The application of the method of colchicine baths to studies of karyotypes of the young of two mullet species (Mugilidae) from the Black Sea. In: Dushkina, L. A. (ed.) Early Life History of Marine Species, pp. 139-149. Sbornick Nauchnih Trudov VNIRO, Moscow.

CANO, J., THODE, G. AND ALVAREZ, M. C. 1982. Karyoevolutive considerations in 29 Mediterranean teleost fishes. Vie Milieu, 32, 21-24.

CATAudella, s. AND CAPANNA, E. 1973. Chromosome complements of three species of Mugilidae (Pisces, Perciformes). Experientia, 29, 489-491.

cataudella, S., Civitelli, M. V. And capanna, E. 1974. Chromosome complements of the Mediterranean mullets (Pisces, Perciformes). Caryologia, 27, 93-105.

CHOUDHURY, R. C., PRASAD, R. AND DAS, C. C. 1979. Chromosomes of six species of marine fishes. Caryologia, 32, 15-21.

DELGADO, J. V., THODE, G., LOBILlO, J., CAMACHO, M. E., Alonso, A. AND RODERO, A. 1991. Detección de la región del organizador nucleolar en cromosomas de la familia Mugilidae (Perciformes): precisiones técnicas. Arch. Zootec., 40, 301-305.

DElgAdo, J. V., MOl.INA, A., LOBIllo, J., ALONSO, A. AND CAMACHO, M. E. 1992. Morphometrical study on the chromosomes of three species of mullet (Teleostei, Mugilidae). Caryologia, 45, 263-271.

HOWELL, W. M. AND BLACK, D. A. 1980. Controlled silverstaining of nucleolus organizer regions with a protective colloidal developer: a 1-step method. Experientia, 36, 1014-1015.

JORDÃO, L. C., OLIVEIRA, C., FORESTl, F. AND GODINHO, H. M. 1992. Caracterização citogenética da tainha, Mugil platanus (Pisces, Mugilidae). B. Inst. Pesca, 19, 63-66.

KLINKHARDT, M., TESCHE, M. AND GREVEN, H. 1995. Database of Fish Chromosomes. Westarp Wissenschaften, Magdeburg.

LAWRENCE, J. B., VIlLNAVE, C. A. AND SINGER, R. H. 1988.
Sensitive, high-resolution chromatin and chromosome mapping in situ: presence and orientation of two closely integrated copies of EBV in a lymphoma line. Cell, 52, 51-61.

MAYR, B., KALAT, M. AND RAB, P. 1988. Heterochromatins in three species of salmonids. Theor. Appl. Genet., 71, $703-707$.

OHNO, s. 1974. Protochordata, Cyclostomata and Pisces. In: John, B. (ed.) Animal Cytogenetics, vol. 4. Gebrüder Borntraeger, Berlin.

PENDÁs, A. M., MORÁN, P. AND GARCíA-VÁZQUEZ, E. 1993a. Ribosomal RNA genes are interspersed throughout a heterochromatic chromosome arm in Atlantic salmon. Cytogenet. Cell Genet., 63, 128-130.

PENDÁs, A. M., MORÁN, P. AND GARCÍA-VÁZQUEZ, E. 1993b. Multi-chromosomal location of ribosomal RNA genes and heterochromatin association in brown trout. Chromosome Res., 1, 63-67.

PHILliPS, R. B. AND HARTLEY, S. E. 1988. Fluorescent banding patterns of the chromosomes of the genus Salmo. Genome, 30, 193-197.

REED, K. M. AND PHILLIPS, R. B. 1995. Molecular characterization and cytogenetic analysis of highly repeated DNAs of lake trout, Salvelinus namaycush. Chromosoma, 104, 242-251.

ROSSI, A. R., CROSETTI, D., GORNUNG, E. AND SOLA, L. 1996. Cytogenetic analysis of global populations of Mugil cephalus (striped mullet) by different staining techniques and fluorescent in situ hybridization. Heredity, 76, 77-82.

SAlVADORI, S., DEIANA, A. M., COLUCCIA, E., FlORIDIA, G., ROSS1, E. AND ZUFFARD1, O. 1995. Colocalization of (TTAGGG) telomeric sequences and ribosomal genes in Atlantic eels. Chromosome Res., 3, 54-58.

SOLA, L., ROSSI, A. R., IASELLI, V., RASCH, E. M. AND MONACO, P. J. 1992. Cytogenetics of bisexual/unisexual species of Poecilia. II. Analysis of heterochromatin and nucleolar organizer regions in Poecilia mexicana mexicana by C-banding and DAPI, quinacrine, chromomycin $\mathrm{A}_{3}$, and silver staining. Cytogenet. Cell Genet., 60, 229-234.

SUMNER, A. T. 1972. A simple technique for demonstrating centromeric heterochromatin. Exp. Cell. Res., 75, 304-306.

tortonese, E. 1975. Fauna d'Italia, Vol. XI (2): Pesci Ossei. Edizioni Calderini, Bologna. 